\title{
Phronesis
}

\section{Quelle place pour les fondements de l'éducation dans le travail éducatif aujourd'hui ?}

\section{Lucie Roger}

Volume 5, numéro 2, 2016

Quelle place pour les fondements de l'éducation dans le travail éducatif aujourd'hui?

URI : https://id.erudit.org/iderudit/1038134ar

DOI : https://doi.org/10.7202/1038134ar

Aller au sommaire du numéro

Éditeur(s)

Université de Sherbrooke

Champ social éditions

ISSN

1925-4873 (numérique)

Découvrir la revue

Citer ce document

Roger, L. (2016). Quelle place pour les fondements de l'éducation dans le travail éducatif aujourd'hui ? Phronesis, 5(2), 1-3. https://doi.org/10.7202/1038134ar d'utilisation que vous pouvez consulter en ligne. 


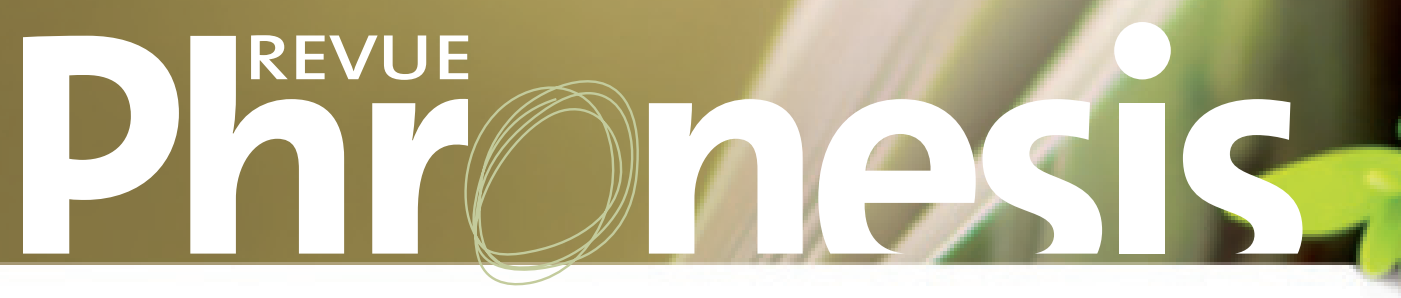

Volume 5, numéro 2 | 2016

\section{INTRODUCTION}

Numéro coordonné par: Lucie ROGER

Université du Québec à Montréal

405 Rue Sainte-Catherine Est,

Montréal, OC H2L 2C4

Roger.lucie@uqam.ca.

\section{Quelle place pour les fondements de l'éducation dans le travail éducatif aujourd'hui ?}


Décrire, analyser et comprendre le travail éducatif dans les professions de l'humain invite à une lecture d'un agir professionnel en situation intégrant dialectiquement la saisie de plusieurs processus ; anticipation, conception, action, réflexion critique. Le travail éducatif vise à créer les conditions d'un apprentissage transformateur chez autrui. II convoque différents savoirs. Mais quels fondements sont à l'origine de ces savoirs sollicités par les professionnels du travail éducatif ? Les doctrines et conceptions éducatives comme les idées pédagogiques traversent l'histoire de ces professions et les histoires de ceux et celles qui les exercent. Or, force est de constater que ces conceptions ou doctrines éducatives, ces idées ou théories pédagogiques s'accompagnent souvent de deux ambitions : l'innovation et l'efficacité. Ces deux ambitions soulignent sans doute la part d'utopie constitutive de tout projet d'éducation et dès lors de tout travail éducatif. Mais elles nous encouragent aussi à déceler en elles l'origine patrimoniale de leurs thèses ou propositions. Nous proposons dans ce numéro une lecture de quelques conceptions éducatives et idées pédagogiques exprimant ces ambitions d'innovation et d'efficacité que nous souhaitons soumettre au double regard critique, celui des penseurs de l'éducation et celui des pédagogues que sont les professionnels de l'humain.

Mathilde Cambron-Goulet propose de comprendre les prémisses de l'enseignement à distance à partir de l'étude des pratiques épistolaires d'Épicure. Les textes d'Épicure sont annonciateurs d'idées fortement situées depuis dans le vocabulaire de l'ingénierie des formations à distance : individualisation de la formation, prise en compte des dimensions cognitives du formé, développement d'une communauté apprennante.

Stéphane Martineau et Alexandre Buysse mettent en tension les systèmes éducatifs actuels et les conceptions rousseauistes de l'éducation. Les systèmes éducatifs actuels cherchent-ils à développer l'autonomie et la liberté de chacun ? Cherchent-ils à faire des élèves des citoyens conscientisés et prêts à agir dans la société ? Si les sociétés changent et évoluent, les valeurs fondamentales de l'Éducation défendues par Rousseau sont-elles encore présentes dans nos systèmes éducatifs post-modernes?

Marc Boutet, à partir d'un récit d'expérience, nous invite à redéfinir l'approche éducative par projet selon John Dewey. Les projets dont parle Dewey prennent appui sur les intérêts des élèves. Ces intérêts expriment leurs expériences. Chez Dewey, le projet est au service du développement individuel de l'enfant. Il sert l'objectif de contribuer au développement d'une communauté d'apprentissage comme une configuration de la démocratie.

Philippe Maubant analyse l'usage du concept d'alternance en formation. II montre combien les liens entre culture et éducation, sous le regard de trois penseurs de l'Éducation Nouvelle, Pestalozzi, Freinet et Dewey, permettent de repenser l'alternance au-delà de nos lectures habituelles, souvent enfermées par le modèle de l'ingénierie de formation. L'alternance, pensée comme rapport dialectique entre culture et éducation, se présente alors comme une pédagogie au service du développement humain.

Lucie Roger s'intéresse à la présence de la culture dans deux curricula : celui de l'école québécoise et le curriculum de la formation des enseignants au Québec. Elle propose une lecture anthropologique des rapports entre culture et éducation à partir d'une analyse de ces deux documents curriculaires. Elle cherche à définir ainsi le construit de maître cultivé et à en identifier les contours à des fins de modélisation en convoquant les travaux de Gaston Bachelard. Un maître cultivé, pour l'anthropologie culturelle, c'est avant tout un maître qui sait contribuer au développement, chez l'élève, d'une compréhension critique du monde, un monde qu'il habite et qu'il contribue à construire. 
Enfin, Malgozarta Piasesca expose les défis de l'éducation européenne à travers l'analyse de l'articulation de trois perspectives : intégrer le monde, habiter l'Europe et être bien chez-soie. Les racines mythico-historico-culturelles de l'idée d'européanité font de l'idée d'éducation européenne un projet nourri de ruptures, de contradictions et de tensions auxquelles s'ajoutent d'autres réalité comme la mondialisation, l'occidentalisation, la sécularisation et l'américanisation. L'école, comme reflet de la culture, est le lieu de transformations sociales. Elle doit être dès lors un espace de dialogue, ouvert et multiculturel, porteur de valeurs humanistes. L'école doit contribuer à développer «une sagesse», une compréhension interculturelle du monde, autrement dit une pensée imaginative.

On peut ainsi comprendre, à travers ces articles, que les fondements de l'éducation sont encore — voire plus que jamais — utiles aujourd'hui. Les fondements nous permettent à la fois de retrouver les aspects culturels intimement liés à l'éducation, tant ses origines, que la construction de la culture (ou des cultures) présente (s). Ré-interroger les fondements permet de retrouver les idées de citoyenneté, de solidarité sociale, de coopération, de communautés apprenantes, mais aussi leurs mise en oeuvre dans différents systèmes et différents contextes. Les fondements sont indispensables pour la construction d'un esprit critique et le développement d'une «imagination empathique» (Martha Nussbaum, 2011), c'est-à-dire la capacité de voir l'humanité là où elle est. Si l'éducation rencontre aujourd'hui des défis de taille, elle ne pourra les relever sans recourir à son histoire, ses racines et à tous les penseurs qui, au cours des périodes mouvementées de l'Histoire de l'humanité, ont déjà posé toutes les questions qui animent encore aujourd'hui les sociétés modernes.

Nussbaum, M. (2011). Les émotions démocratiques. (Traduite de l'anglais par Solange Chavel). Paris: Climats. 